\title{
Quilombo: da ilegalidade à cidadania
}

Maria Ester Santana Silveira Nascimento

\section{Resumo}

Nos últimos anos, temos presenciado a introdução, em nosso cotidiano social, da palavra "quilombola". Timidamente, as pessoas vão tomando consciência dessa realidade que, por anos, ficou apagada. A Constituição de 1988 abriu o caminho para as expressões "quilombo" e "quilombola". O que norteia este texto é a necessidade de conhecer os motivos da retomada do conceito de quilombo e a importância de seu uso na atualidade. A comparação entre dois tempos históricos de uso desse conceito é o caminho escolhido para esse conhecimento.

\section{Palavras-chave}

Quilombo. Remanescentes de Quilombo. Ressemantização.

1. Mestre em Desenvolvimento Social pela Universidade Estadual de Montes Claros, professora nas Faculdades Pitágoras de Montes Claros. E-mail: msantanasn@hotmail.com. 


\title{
Maroon: lawless to right
}

Maria Ester Santana Silveira Nascimento*

\begin{abstract}
Recent years have witnessed the introduction, in our everyday social life, the word "maroon". Tentatively people will become aware of this reality that for years has been erased. The 1988 Constitution paved the way for these expressions "maroons" and "maroon". What guides this text is the need to know the reasons for the resumption of the Maroons concept and the importance of its use today. The comparison between two historical periods of this concept use is the path chosen for this knowledge.
\end{abstract}

\section{Keywords}

Maroons. Remnants of Maroons. Resemantization.

\footnotetext{
* Master in Social Development at the State University of Montes Claros, professor at the Faculdades Pitágoras
} of Montes Claros. E-mail: msantanasn@hotmail.com 


\section{Introdução}

O grupo de remanescentes quilombolas - Família dos Amaros - na cidade de Paracatu, afirma que de posse da terra que recebeu irá desenvolver um "quilombo contemporâneo". A afirmação de desejo de construção de um quilombo contemporâneo sugere oposição ao antigo. A história há muito eliminou a forma antiga de quilombo. Por que então, afirmar a construção de um quilombo contemporâneo? O que há de semelhante e distinto entre as duas realidades: tradicional e contemporânea?

Como apreendemos da literatura histórica, o quilombo foi, em sua origem, o resultado de um movimento social cujo cerne era a resposta negativa de escravos e pessoas pobres ao sistema opressor e escorchante. Em sua concretude, o quilombo foi mais que isso. Na atualidade, a palavra e o próprio espaço físico do quilombo tornaram-se "comunidade remanescente de quilombo". Resultado da mobilização social que busca uma resposta reparadora (positiva) da história e da sociedade que os negou.

Pensar em quilombo sempre nos remete ao termo resistência, visto que, em nossa literatura histórica, antropológica e sociológica, a fuga e a vida nos quilombos representam relevantes atitudes de resistência utilizadas pelos negros contra o sistema escravista, o que gerou uma imagem negativa de seus componentes.

Apesar de cientes de que o quilombo não representou apenas resistência ao sistema escravista, mas também um local de produção para o seu abastecimento, relacionando-se em todo o tempo a vários segmentos sociais, sua ideia de marginalidade não foi abolida com o fim da escravidão e seus integrantes continuaram vistos como marginais por um longo período. Na realidade, boa parte deles tornaram-se camponeses pobres, posseiros e clandestinos, ocupando áreas que a sociedade dominante desconsiderava como de interesse.
No início século $X X$, a realidade dessas comunidades começou a mudar, desta vez devido ao interesse da sociedade "branca" em expansão para territórios antes abandonados. Agora, não houve fuga, buscouse a evidenciação favorecida pelos novos movimentos sociais que, durante o referido século, foi-se fortalecendo e, ao final, ganhou fôlego com a efervescência política do momento.

A culminância dessa nova luta foi a lembrança desses sujeitos no Art. 68 dos Atos das Disposições Constitucionais Transitórias (ADCT) (Constituição Federal de 1988) que transformou, de uma só vez, o quilombo histórico em território de importância fundiária, cultural e política, ao mesmo tempo em que transformou seus integrantes em sujeitos de direito com a garantia de ocupação desse território.

A partir da ADCT, um longo debate foi levantado.Questõesqueiamdesdeadúvidasobre o que realmente deveria ser uma comunidade quilombola até as que se referiam a quem pertenceria o direito de se titular quilombola foram levantadas. Dentre elas, a necessidade de revisão dos conceitos que caracterizaram o período da escravidão. É nesse contexto que o termo quilombo foi retomado exigindo a criação de um novo conceito para o mesmo.

A comparação entre dois tempos históricos do termo quilombo: até 1888, fim da escravidão; após 1988, advento da nova Carta Constitucional brasileira, será o método utilizado para explicarmos as razões para a retomada e ressemantização do termo quilombo a partir da década de 1980.

A construção deste texto baseia-se, preferencialmente em Almeida (2002), Arruti (2005) e O'Dwyer (2002), nos estudos das áreas de antropologia e sociologia, assim como no enfoque dado ao debate que se faz em torno da elaboração do novo conceito de quilombo. 
Outro aspecto relevante é a identificação do que deve conter esse novo conceito e a quem deve ser delegada a tarefa de sua elaboração. Como base teórica para o campo histórico, destacamos os Gomes (2005) e Silva (2009).

\section{O conceito de quilombo no Brasil escravista}

O'Dweyr (2002, p. 9, grifo no original) afirma que "até recentemente, o termo quilombo era de uso quase exclusivo de historiadores e demais especialistas." A Constituição de 1988 mudou essa situação, quando coloca no Art. 68, dos Atos das Disposições Transitórias da Constituição, que:

[...] aos remanescentes das comunidades dos quilombos que estejam ocupando suas terras é reconhecido a propriedade definitiva, devendo o Estado emitir-lhes os títulos respectivo (BRASIL, 1988, não paginado).

Assim, várias áreas do conhecimento tiveram que voltar sua atenção ao tema que deixa de ter um significado apenas vinculado ao passado escravista e passa a ter um sentido sociocultural. Antes de falarmos sobre essas mudanças, vejamos o que a historiografia pode nos oferecer sobre o que era um quilombo em sua forma de origem.

Os historiadores Flávio dos Santos Gomes (2005) e Clóvis Moura (1993) afirmam que as sociedades escravistas do período da colonização europeia sobre a América foram marcadas por práticas de fugas que acabaram formando comunidades fugitivas.

Assim foi na Venezuela com os cumbes; na Colômbia com os palenques; no Caribe inglês e EUA com os maroons; no Caribe Francês com a marronage e em Cuba com os cimarrones. No Brasil, desde o período colonial, tais comunidades de fugitivos escravos receberam as denominações de quilombos e/ou mocambos (GOMES, 2005, p. 449, grifos no original).
Na Colômbia, Cuba, Haiti, Jamaica, Peru, Guianas, finalmente onde quer que a escravidão existisse, o negro marron, o quilombola, portanto, aparecia como sinal de rebeldia contra o sistema que o escravizava. Em Cuba, eram os palenques, muitos deles famosos (MOURA, 1993, p. 11, grifos no original).

Gomes (2005) apresenta, ainda, a tradução do termo "quilombo/mocambo", que, "na maioria das línguas bantu da África Central e Centro-Ocidental quer dizer 'acampamento'" (2005, p. 449). Acampamento é uma expressão muito próxima do conceito jurídico formal usado no Brasil, desde o século XVIII, para definir um quilombo. Nas descrições que faz, esse conceito procura provar que em todos os seus aspectos o quilombo era uma representação da ilegalidade do negro: fugitivo, vivendo em bando, sem moradia fixa e nem pilões para provimento do sustento do dia.

Esse conceito, composto de elementos descritivos, foi formulado como uma "resposta ao rei de Portugal" em virtude de consulta feita ao Conselho Ultramarino, em 1740. Quilombo foi formalmente definido como "toda habitação de negros fugidos, que passem de cinco, em parte despovoada, ainda que não tenha ranchos levantados e nem achem pilões nele" (ALMEIDA, 2002, p. 47, grifo no original).

Para Almeida (2002, p. 43-44), essa definição de quilombo ficou "frigorificada" no tempo e, ao que tudo indica, foi a base não só da literatura acadêmica como também das questões jurídicas sobre o termo até que, na década de 1980, quando o Plano Nacional de Reforma Agrária esbarrou em uma situação que não condizia com os preceitos jurídicos já instituídos de que a estrutura agrária no Brasil, de acordo com o IBGE, deveria se encaixar em duas categorias: estabelecimentos e imóveis rurais. Sob pressão dos movimentos camponeses, chegou-se à criação de um novo termo para o que até então permanecia 
descaracterizado: "ocupações especiais, que entre outras situações designava as chamadas terras de pretos, terras de santo e terras de índio" (ALMEIDA, 2002, p. 45, grifos no original).

Uma verificação mais acurada pode nos mostrar que, no decorrer do tempo, tanto no período colonial, como no período do Brasil Império, a "ilegalidade" do quilombo, em vários momentos, foi, de certa forma, relativizada em razão das circunstâncias econômicas.

O sistema repressor não fala por si só e precisa de suporte econômico. Escasseando os recursos financeiros dos grandes proprietários, os mecanismos de coerção e justiça privada não funcionavam com a mesma intensidade (ALMEIDA, 2002, p. 59).

Não são raras as situações de acordos e negociações entre senhores e quilombos, demonstrando que o segundo representou, também, micro sociedades camponesas fornecedoras de alimentos, abastecendo os mercados locais e socorrendo os senhores em momentos em que a economia exigia destes a necessidade de

assegurar a alimentação do escravo por vias externas, isto é, comprando a produção do campesinato periférico à grande plantação e dos comerciantes que transacionavam inclusive quilombolas (ALMEIDA, 2002, p. $51)$.

Para Gomes (2005, p. 457) é possível afirmar que, em muitas regiões brasileiras, "alguns quilombos foram quase reconhecidos como comunidades de camponeses independentes". E mais:

[...] Ainda durante a escravidão e avançando o século $\mathrm{XX}$, muitos quilombolas eram quase reconhecidos como pequenos camponeses, pois iam frequentemente e com a maior liberdade aos povoados circunvizinhos comerciar seus produtos, comprar pólvora e munição, e alguns deles até trabalhavam por vezes para fazendeiros locais em troca de proteção, dinheiro e mantimentos (GOMES, 2005, p. 460).

Situações como essas nos permitem crer na produçãoquilombola paralelaà grande produção sistematizada, voltada para a exportação.

[...] como unidade produtiva, o quilombo desenvolvia, internamente, uma série de atividades para se manter e alimentar sua população. Tinha seu setor artesanal, que se desenvolvia constantemente, metalurgia, tecelagem: finalmente, organizava-se internamente para conseguir, em caso de isolamento ou de guerra, manter-se sem grandes crises internas de produção. Essa dupla atividade do quilombo - de um lado, mantendo intercâmbio com outras unidades populacionais e produtivas e, do outro, desenvolvendo sua própria economia interna - permitiu-lhe possibilidade de sobrevivência na sociedade escravista que o perseguia (MOURA, 1993, p. 26).

Na trilha dessa crença, na relação de quilombo e campesinato, podemos observar que, com a abolição, a necessidade de fuga e a formação de quilombos, no sentido de resistência ao sistema escravista, perderam o sentido. De negros e pobres fugitivos, a maior parte desses grupos passaram a camponeses pobres e invisíveis ao Estado, carregando, culturalmente, um problema que, segundo Almeida, está no fato de que

esses cinco elementos que compõem o antigo conceito de quilombo funcionaram como definitivos e definidores de quilombo. Jazem encastoados no imaginário dos operadores de direito e dos comentadores com pretensão científica (ALMEIDA, 2002, p. 49).

Os referidos elementos seriam, nas falas de Almeida (2002), a fuga; a quantidade que em princípio foi determinado que seria a reunião de cinco ou mais, posteriormente, esse número foi reduzido para dois; a localização isolada; a moradia; e a forma de sobrevivência 
representada pelos "pilões" que este podia conter, representando a forma de sustento.

Em sua pesquisa, Almeida (2002) comprova que o quilombo ultrapassou a representação ultramarina, rompendo com a caracterização desses cinco elementos. Além disso, o autor apresenta provas de que, pelo Código Criminal do período imperial, quilombo é diferente de insurreição, o que seria, na época, uma concreta afronta ao sistema e, embora durante um longo período, o quilombo o fosse assim e visto também como tal, no decorrer do tempo, relacionaram-se frequentemente com a sociedade brasileira. Nada disso foi observado. Uma situação que poderia ter sido resolvida no passado, quando da criação da Lei de Terras de 1850 ou quando da abolição da escravatura e, por fim, na primeira constituição republicana. Somente um século depois, nas últimas décadas do século $X X$, essa questão foi posta em evidência nos ADCT da Carta Constitucional de 1988. A partir daí, outro significado foi indicado para o termo quilombo. Um novo conceito foi suscitado.

Todavia, com tantas mudanças, resta-nos o questionamento de Almeida (2002, p. 46): Qual o esquema interpretativo disponível e apropriado para dar conta dessa contingência histórico-sociológica? Quer dizer, qual o conceito de quilombo que estava em jogo?

\section{De quilombo a comunidades de remanescentes de quilombo}

A expressão "quilombo" foi deixada para trás há algum tempo e novas semânticas foram lhes sendo dadas. Primeiro foi "terra de preto", como já nos referimos acima, e, agora, é mais comum a expressão "comunidades remanescentes de quilombo" ou "comunidades quilombolas". NaspalavrasdeArruti(2005, p. 26):

Categoria social relativamente recente representa uma força social relevante no meio rural brasileiro, dando nova tradução àquilo que era conhecido como comunidades negras rurais (mais ao centro e sudeste do país) e terras de preto (mais ao norte e nordeste), que também começa a penetrar o meio urbano, dando nova tradução a um leque variado de situações que vão desde as antigas comunidades negras rurais atingidas pela expansão dos perímetros urbanos até bairros em torno dos terreiros de candomblé.

Nota-se que, tanto no passado quanto no presente, o conceito de quilombo não alcança uma representação fidedigna se não passar pelos sujeitos que o compõem. As várias formas de formação de quilombos, antes e depois da abolição da escravatura, e as transformações que estes sofreram ao longo do tempo são base para um grande número análise e reflexão sobre a elaboração de um novo conceito de quilombo e sobre o que realmente poderia representar um quilombo nos dias atuais, com preocupações referentes à amplitude que o conceito pode conter para não deixar de atender a essas possíveis variações de grupos quilombolas que a lei deve abranger. Arruti (2005) apresenta duas correntes que, segundo ele, são opositoras apenas politicamente, em relação ao que deve ser o quilombo nos dias atuais:

De um lado temos a posição primordialista, que está ligada a um uso do quilombo (...) como ícone da "consciência" e da "cultura negra", a uma crítica à democracia racial, que faz com que o "artigo 68" esteja associado à ideia de uma representação da dívida histórica que o sistema escravista deixou ao Estado e à sociedade brasileira. De outro, temos a posição ressemantizadora, que resulta da equação das expressões "terras de uso comum", categorias de "auto-atribuição", novas etnias e está associada àquela outra genealogia² do "artigo 68" (ARRUTI, 2005, p. 100- 101, grifos no original). 
esses dois grupos é pautado em um largo espaço de consensos. Tanto um quanto o outro buscam a proteção cultural e a regulamentação fundiária. A divergência está estabelecida na forma como cada um utiliza o termo "cultura" para a identificação quilombola.

Enquanto para alguns ressemantizadores (para os quais a constituição garante, concomitantemente, os dois aspectos: fundiários e culturais) a regularização dos territórios quilombolas não é uma questão prioritariamente cultural; os primordialistas, responsáveis pela existência do "Artigo 68", preocupam-se, sobretudo,

com a produção de uma identidade e de orgulho racial que têm na recuperação do mundo africano entre nós e no exemplo de resistência o seu foco (ARRUTI, 2005, p. 102).

Para os primordialistas há, antes de tudo, uma relação entre cultura e etnicidade que extrapolaocampodareferência determinadapela constituição e, por isso, buscam uma espécie de alargamento do conceito de quilombo para que a lei possa beneficiar espaços fora da condição camponesa como terreiros de candomblé, monumentos negros, favelas que antes eram espaços de negros e, com a urbanização, foram abarcadas no espaço urbano. Nesse caso,

a afinidade eletiva com a cultura continuaria com a mesma força, sem que isso inviabilizasse um efeito que ultrapassa o pensamento simbólico para alcançar o plano fundiário (ARRUTI, 2005, p. 105, grifos no original).

Ressemantizadores ou culturalistas concordam que a criação de um novo conceito de quilombo deve passar pelos sujeitos e sua autoidentificação como quilombolas. O texto constitucional não evoca apenas a "identidade histórica", que pode ser assumida e acionada pela forma da lei, mas também dá garantia de titulação territorial, condicionada pela relação identitária desses sujeitos com passado e o referido território. Diante disso, entre os antropólogos atuais, há um consenso de aceitação sobre a definição de prática quilombola como grupos étnicos que existem ou persistem ao longo da história como um tipo organizacional, segundo processos de exclusão e inclusão que possibilitam definir os limites entre os considerados de dentro e de fora (O'DWYER, 2002, p. 14, grifos no original).

Essa conceituação inova no que tange a eliminação das diferenças culturais e políticas assinaladas acima e, de acordo com O’Dwyer (2002), revela aos seus sujeitos uma identidade que muitos deles provavelmente desconheciam, passando a ser os próprios os responsáveis pelos critérios que deverão compor o novo conceito de quilombo. Mesmo estando na pauta de muitos debates e estudos, há ainda uma grande dificuldade na definitiva elaboração desse novo conceito. Almeida (2002) segue no mesmo sentido de O'Dwyer (2002) e acredita que

O importante aqui não é tanto como as agências definem, ou como uma ONG define, ou como o partido político define e sim como os próprios sujeitos se autorrepresentam e quais os critérios político-organizativos que norteiam suas mobilizações e forjam a coesão em torno de uma certa identidade (ALMEIDA, 2002, p. 68).

Nesse sentido, o novo conceito elaborado deverá dar conta de proporcionar aos seus sujeitos as seguintes condições:

2. Essa "outra genealogia" está relacionada com o que o autor apresenta em sua obra Mocambo, que, segundo um constituinte integrante da comissão de Índios, Negros e Minorias, o "artigo 68" dos ADCT teria sido incorporado à Carta "no apagar das luzes", em uma formulação "amputada" e, mesmo assim, apenas em função de intensas negociações políticas levadas por representantes do movimento negro do Rio de Janeiro (ARRUTI, 2005, p. 67). 
[...] a) assumir a agência de serem os produtores culturais da identidade afirmadora de sua territorialidade, b) estabelecer articulações com o movimento social da região em que se encontrem inseridas para constituir-se como ponto de uma trama política de defesa dos direitos dos povos e das comunidades tradicionais, c) apoiar-se em mediações individuais e/ou institucionais para fazer a passagem de um grupo social isolado para um grupo social que dialoga com instâncias do Estado Nacional, d) resgatar pela memória coletiva, práticas, saberes e manifestações culturais que evidenciam a singularidade cultural e que afirmem sua tradicionalidade, e) manter-se coeso nos embates com outras categorias sociais que discutem o território em que sua historicidade se encontre inscrita e f) inserir-se nas dinâmicas econômicas regionais e nacionais, como parte de suas estratégias de reprodução materialista, sem submeter-se à lógica capitalista hegemônica [...] (COSTA, 2009, p. 11).

Em sintonia com essa capacidade de ação, o novo conceito de quilombo reflete a nova realidade social que se faz presente, na qual o sujeito se autodefine e exige, na diferença, o direito de igualdade, uma garantia constitucional.

\section{Por que retomar e ressemantizar o termo quilombo}

A comparação proposta entre os dois períodos aqui apresentados tinha como objetivo justificar a retomada e a ressemantização do termo quilombo nos dias atuais. Durante esse processo, foi possível destacar a inversão significativa que o conceito de quilombo sofreu de um contexto para o outro. Enquanto, em um primeiro momento, sinaliza a ilegalidade dos sujeitos que define, no segundo, garante sua legalidade como sujeitos de direito. Isso não foi contingente, fez parte de um processo de retomada do que representou o quilombo para os oprimidos do passado escravista, de maneira mitológica, sendo o objeto de representação desse mito, o Quilombo de Palmares.
Essa inversão simbólica do próprio quilombo como metáfora é fruto de um movimento intelectual e político que percorreu todo o século XX sob a bandeira de duas perspectivas: a que via o quilombo como resistência cultural e a que via o quilombo como resistência política.

É, então, o caráter de resistência que transforma em simbólico e mitológico o quilombo. No decorrer histórico dessa construção, o quilombo foi sendo transformado de espaço ilegal a espaço de confraternização, solidariedade e convivência fraternal, sem deixar de lembrar sua significação como espaço representativo da luta de classes.

O centenário da Abolição permitiu que "a simbologia dos quilombos - tornada grande reserva mitológica para a construção de uma identidade positiva do negro brasileiro" (HASENBALG, 1992, p. 144) - pudesse ser "projetada definitivamente nos planos nacional e oficial" (ARRUTI, 2005, p. 78). A culminância do centenário da Abolição com a promulgação da nova constituição brasileira foi o cenário oportuno para a ratificação desse projeto.

\section{Considerações Finais}

Assim como Franco (2000), consideramos, neste trabalho, que a perspectiva histórica e a perspectiva sociológica completam-se, por meio do método comparativo, tendo a história como base, preservando a especificidade temporal do mesmo fenômeno, visualizando-o nas relações que estabelece com outros fenômenos, sob a ação de sujeitos individuais e coletivos.

Com base nesse procedimento, foinos possível identificar as visões sociopolíticas oferecidas pelo conceito de quilombo em dois tempos distintos. No primeiro momento, notase que o conceito é desfocado da realidade pela necessidade de impor uma ordem que atendesse os interesses dominantes. No segundo momento, nota-se a busca pela correção e acerto 
na elaboração do novo conceito, colocando no centro desse processo os sujeitos de interesse.

Esse percurso foi a base para que chegássemos à compreensão dos motivos da retomada e da ressemantização do termo "quilombo" nos dias atuais que, em princípio, pelo artigo constitucional, pouco distinguiu sua significação histórica de sua significação contemporânea. Após longos debates e desenvolvimento de uma legislação supraconstitucional, o uso do termo revelou sua força simbólica para o reconhecimento do descaso histórico para com esses sujeitos, assim como sua importância na recuperação identitária dos mesmos e a garantia de direitos. Considerando que a responsabilidade da construção do novo conceito dar-se-á pelos sujeitos que dele se beneficiaram, concluímos que até o presente momento encontra-se em processo de elaboração. Em princípio, por razões que envolvem a definição do que realmente deverá ser espaço de remanescentes de quilombo e, além disso, pelos entraves políticos sociais que tornam morosas as transformações sociais no país. Mas esse é outro assunto e não cabe aqui sua discussão.

\section{Referências}

ALMEIDA, A. W. B. de. Os quilombos e as novas etnias. In: O'DWYER, E. C. (Org.). Quilombos: identidade étnica e territorialidade. Rio de Janeiro: Editora da FGV, 2002.

ARRUTI, J. M. Mocambo: antropologia e história do processo de formação quilombola. Bauru, SP: EDUSC, 2005.

COSTA, J. B. de A. A (des)invisibilidade dos povos e das comunidades tradicionais: a produção da identidade, do pertencimento e do modo de vida como estratégia para efetivação de direito coletivo. Montes Claros: Unimontes, 2009.

FRANCO, M. C. Quando nós somos o outro: questões teórico metodológicas sobre os estudos comparados. Educação \& Sociedade, Campinas, Ano XXI, n. 72, ago. 2000.

GOMES, F. dos S. Sonhando com a terra e construindo a cidadania. In: PINSKY, J; PINSKY, C. B. (Org.). História da cidadania. São Paulo: Contexto, 2005.

MOURA, Clóvis. Quilombos: resistência ao escravismo. São Paulo: Ática, 1993.

O'DWYER, E. C. Os quilombos e a prática profissional dos antropólogos. In: . (Org.).

Quilombos: identidade étnica e territorialidade. Rio de Janeiro: Editora da FGV, 2002.

SILVA, E. Negociação e conflito: a resistência negra no Brasil escravista. In: SILVA, E.; REIS, J. J. São Paulo: Cia. das Letras, 2009.

Submetido em 28 de junho de 2012.

Aprovado em 28 de setembro de 2012. 